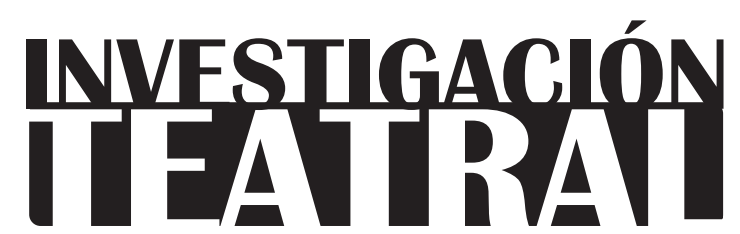

Revista de artes escénicas y performatividad

Vol. 11, Núm. 18

octubre 2020-marzo 2021

Segunda época

ISSN impreso: 1665-8728

ISSN electrónico: 2594-0953

Universidad Veracruzana

\title{
Ciclo Escena y Memoria: una rebeldía amorosa
}

\author{
Mauro Alegret*
}

* Departamento de Teatro, Facultad de Artes,
Universidad Nacional de Córdoba, Argentina.
e-mail: mauroalegret@gmail.com

Recibido: 27 de marzo 2020

Aceptado: 16 de julio de 2020

Doi: https://doi.org/10.25009/it.v11i18.2648 


\title{
Ciclo Escena y Memoria: una rebeldía amorosa
}

\section{Resumen}

En el presente trabajo se abordan dos eventos teatrales: la representación de la obra Villa, del dramaturgo chileno Guillermo Calderón, y el Ciclo Escena y Memoria, coordinado por Jorge Villegas. Ambos eventos tuvieron lugar en el campo teatral independiente de la ciudad de Córdoba, Argentina, durante el año 2019. Desde una perspectiva sociohistórica abordamos la relación de dichos eventos con el ejercicio de la memoria en la ciudad. De Villa retomamos las actuales inquietudes respecto al uso político de los sitios de la memoria, para formular la pregunta: ¿es posible representar el horror del terrorismo de Estado? Del Ciclo nos interesan las redefiniciones respecto al cruce entre teatro y militancia política, y la habilitación de nuevos espacios de comunidad social a partir del dolor de los cuerpos.

Palabras clave: Sitios de memoria; derechos humanos; teatro independiente; cuerpos; Argentina.

\section{The Performing Arts and Memory Cycle: an Amorous Rebellion}

\begin{abstract}
This article addresses two theatrical events: the play Villa, by Chilean playwright Guillermo Calderón, and the Performing Arts and Memory Cycle, coordinated by Jorge Villegas. Both were produced in 2019 as part of the independent theater scene in the city of Córdoba, Argentina. These events are discussed from a socio-historical perspective, in order to understand the how they are related to the city's collective memory. In Villa it's possible to identify the political use of the memory sites and how Calderón works with a fundamental question: is it possible to represent the horror of State terrorism? In the Performing Arts and Memory Cycle, the author discusses the intersection between theatre and political militancy, and the enabling of new spaces for social community where bodies have been subjected to pain.
\end{abstract}

Keywords: Sites of memory; human rights; independent theater; bodies; Argentina. 


\section{Ciclo Escena y Memoria: una rebeldía amorosa}

El teatro es un espacio a ser habitado.

Hay algo de lo humano que nos jugamos en cada ensayo, esto es una militancia para mí.

Daniela Martín

\section{Introducción}

ería desafortunado creer que los reclamos por justicia en materia de derechos humanos ya no son necesarios en la actualidad de América del Sur. La opresión de las $\bigcup$ lógicas del "colonialismo interno" (Quijano 265) protagonizadas por el imperialismo global, pero asumidas a la perfección por las castas locales de empresarios, cleros, políticos y medios masivos de comunicación, generan circunstancias propicias para que la violencia por parte del Estado sea un tema vigente.

Hoy día, en la ciudad de Córdoba, Argentina, parece inconcebible imaginar un calendario anual sin actos públicos en torno a la memoria histórica. Las marchas del 24 de marzo, los trascendentales juicios a los genocidas o la presencia de los organismos por los derechos humanos en la vida política, es constante y valiosa. No obstante, persiste por parte de los sectores de poder la tendencia de silenciar y distorsionar la historia de las voces oprimidas durante la dictadura. Siguiendo a Eric Selbin: "tradicionalmente, la his- 
toria ha sido constituida desde arriba, escrita por los victoriosos, orquestada por los poderosos e interpretada por la población" (21). A pesar de las sostenidas manifestaciones y acciones sociales de los mencionados organismos, no se consigue quebrar la historia oficial y sus consecuentes sanciones sociales, gestada originalmente por el gobierno militar de facto y sostenida obsecuentemente por los sectores más conservadores de la ciudad a lo largo de los años. Es que estos sectores, tanto en Argentina como en otros países de Latinoamérica, están constituidos por los grupos económicos próximos a las esferas de poder más férreas y, a grandes rasgos, no han sufrido cambios sustanciales respecto a los años de las dictaduras. Las familias y grupos empresariales de los presidentes Macri (Argentina) o Piñera (Chile), o el ex militar Jair Bolsonaro (Brasil), constituyen ejemplos elocuentes. Sus estrategias empresariales, avasallantes e impunes, están fuertemente consolidadas alrededor del poder. Esto les permite continuar operando económicamente, y cuando cuestiones políticas se ponen en su camino, no dudan en recurrir a la violencia. Violencia que se ejerce sobre sectores de la población ideológica y económicamente distanciados, e identificados con "los subversivos" de antaño. En pocas palabras: la violencia, antes ejercida por el Estado de facto, encuentra otras estrategias en el presente.

Luego de las primeras desapariciones forzadas durante la dictadura, algunas madres y abuelas, reunidas en la Plaza de Mayo de la ciudad de Buenos Aires, comenzaron a visibilizar el reclamo y exigir la aparición con vida de sus familiares. Estas acciones se potenciaron con el retorno de la democracia en el país, en el año 1983. Posteriormente se proyectaron a lo largo de las décadas de los años 80, 90 y comienzos del siglo xxi. Se constituyeron así varias organizaciones por los derechos humanos, como Madres y Abuelas de Plaza de Mayo, H.I.J.o.s., la Asamblea Permanente, la Comisión Provincial por la Memoria, por nombrar sólo a algunas. Estos organismos, asociados en el imaginario común a sectores sociales de izquierda, socialistas o comunistas, también cercanos al peronismo, lograron resistir a los embates del poder y fueron resignificando su identidad en la vida social a lo largo de los años. Su militancia y persistencia en el ejercicio de la memoria, la repetición del recuerdo (anulando las distancias con el terror del pasado) y su actitud inflexible de no abandonar los reclamos, finalmente provocó un movimiento en el seno social que recientemente logró cosechar un reconocimiento, insuficiente por las dimensiones del horror, pero válido y de peso. Este reconocimiento se relaciona, entre otras cosas, con la tarea de revisionismo histórico, la visibilización de relatos y de la voz de las víctimas (el libro Nunca más, por ejemplo, pero también todas las investigaciones históricas radicadas en los centros de estudios más importantes del país). Así como también con los juicios y prisión común para muchos de los responsables del terrorismo de Estado, y con la incansable lucha por la identidad que logró la recuperación de más de 100 bebés apropiados ilegalmente en los centros clandestinos de detención. 
A lo largo de todo este tiempo y hasta la actualidad, los hacedores del teatro independiente han acompañado las diferentes realidades de los sectores más afectados. Desde el Teatro Abierto en el año 1980, pasando por las obras de Eduardo “Tato" Pavlovski y los Festivales Internacionales de Córdoba, hasta los ciclos de Teatro por la Identidad a comienzos de siglo xxi, entre otros ejemplos, han ido conformando la íntima relación entre los organismos de derechos humanos y el teatro independiente argentino.

En el caso de Córdoba, podemos afirmar que la matriz constitutiva de la práctica teatral independiente tuvo desde sus inicios, en la década de 1960, un férreo compromiso político. Los grupos de creación colectiva como el LTL, Bochinche o Studio I, por nombrar algunos, sedimentaron sus primeras experiencias sobre la concepción de hacer política con el teatro, de convertirlo en "instrumento de transformación social" (Alegret 143). La búsqueda de esta transformación social, próxima ideológicamente a los movimientos revolucionarios de los años 70 y, lógicamente, en contra de los sectores más conservadores de América Latina, sedimentaron un compromiso político en los hacedores, que aún hoy se manifiesta en la práctica teatral cordobesa (por supuesto, con sesgos y redefiniciones). Estas sedimentaciones históricas revelan la familiaridad presente en el trabajo de los hacedores teatrales de la ciudad, respecto al ejercicio de una mirada crítica y comprometida políticamente; y consecuentemente, el acompañamiento a los organismos de derechos humanos. Por mencionar solamente algunas personalidades y poéticas, que acompañan de manera manifiesta la exigencia de juicio y castigo para los responsables del terrorismo de Estado, se encuentran las obras de Toto López y Daniela Martín, la dramaturgia de Soledad González o la variada actividad de las salas Bataclana o el grupo Balbuceando Teatro.

De lo anterior, podemos afirmar que el teatro independiente cordobés posee una importante tradición con el compromiso político y la visibilización de las situaciones de injusticia. Desde esta concepción basal se desprende, por un lado, la configuración de un espacio artístico donde el grupo de hacedores teatrales ofrece espectáculos a una ciudadanía que supone también crítica; y, por otro lado, una actitud insubordinada respecto a los intereses del poder, debido a que justamente: este teatro es independiente de las industrias culturales.

El teatro de Córdoba se vuelve así un territorio amable y sensible a los conflictos sociales internos al grupo social en donde se produce e inscribe y, además un arte "capaz de afirmar su propia voz" (Alegret 152). En este sentido, retomamos los aportes de Juan Mayorga, quien señala:

El teatro no sólo es un arte en que cabe el pensamiento -además de cualquier otra forma de experiencia humana- sino que lo es en un sentido especial, privilegiado. Por- 
que además de hacer sensible la confrontación de visiones del hombre, de la sociedad y del mundo al encarnarlas en personajes que las hacen suyas hasta el límite -hasta la muerte-, es capaz de dar a pensar aquello para lo que todavía no hay palabra, aquello que los filósofos no saben nombrar ("El teatro piensa” 15).

En la asamblea teatral se observan críticamente las concepciones de existencia, convirtiéndose así para los participantes (hacedores y espectadores), en una oportunidad donde preguntar cómo habitamos nuestro mundo, qué ideas tenemos acerca de él, o bien, interrogarnos sobre cómo nos relacionamos con lo demás. En la misma sintonía, Jorge Dubatti afirma:

como espectadores vamos al teatro a relacionarnos con el ser [...] y a producir subjetividad, formas de relacionarnos con el mundo. Los espectadores también "hacemos cosas" con el teatro, el teatro también es parte de nuestras existencias, modela nuestro ethos y nuestra visión de mundo (Introducción 46).

De aquí que, en el contexto de una vida democrática neoliberal, el teatro sea un lugar propicio para la tarea de preguntarse por las responsabilidades de los sectores sociales afectados por la dictadura y, en consecuencia, cuál es el lugar de los artistas teatrales en el complejo ejercicio de la memoria actual.

En el presente trabajo se abordan dos eventos teatrales del teatro realizados en Córdoba: la representación de la obra Villa, del dramaturgo chileno Guillermo Calderón (dirigida por Victoria Monti y estrenada en el Teatro Real de la Ciudad de Córdoba, el día 5 de septiembre 2018), y el Ciclo Escena y Memoria, coordinado por el reconocido director teatral, Jorge Villegas. Ambas experiencias son examinadas bajo la categoría historiográfica de lo que Dubatti denomina Teatro de Postdictadura. Ésta permite plantear una continuidad del horror perpetrado por el gobierno militar, junto con sectores empresarios, eclesiásticos y civiles, en la vida social argentina (y por extensión, latinoamericana). Las consecuencias traumáticas que provocó la dictadura han dejado importantes secuelas:

nada puede ser igual en la Argentina luego de la dictadura militar de 1976-1983 [...] Una vasta zona del teatro actual trabaja sin pausa, y de diferentes maneras, en la asunción del horror histórico, la construcción de memorias del pasado, la denuncia y el alerta de lo que sigue vivo de la dictadura en el presente ("El teatro argentino" 72).

En otros términos, la categoría posibilita contemplar la anulación total de referentes "indiscutidos" o métodos "universales" de creación teatral, ya que éstos poseen un sesgo au- 
toritario y limitador, dos cuestiones demasiado próximas a las leyes dictatoriales. En este sentido, en el Ciclo Escena y Memoria conviven, sin problemas de jerarquía o legitimación, obras como Villa (de carácter representacional) con intervenciones públicas, performances, lecturas de poesía o de música y espectáculos de clown. Como afirma Dubatti: "se sabe que todos los caminos están habilitados, siempre y cuando no ataquen bases humanistas de consenso" ("El teatro argentino" 74).

Este consenso se despliega en el teatro independiente cordobés sobre un profundo compromiso por lo humano y lo que sigue vivo: las memorias, los relatos, la visibilización, el reclamo por la justicia y las necesidades estéticas. Por esto, el análisis de la obra Villa, presentada en el Ciclo Escena y Memoria, permite reflexionar sobre diversos matices políticos de la asamblea teatral, la posibilidad de tomar distancia crítica respecto a las últimas políticas de derechos humanos y la solidaridad afectiva de los cuerpos reunidos, por medio de la cual compartimos y sanamos el dolor en el ejercicio de la memoria.

\section{Los sitios de la memoria ${ }^{1}$ en la encrucijada}

Quien asume la carga de testimoniar por ellos sabe que tiene que dar testimonio de la imposibilidad de [testimoniar.

$Y$ esto altera de manera definitiva el valor del testimonio, obliga a buscar su sentido en una zona imprevista.

Giorgio Agamben

Giorgio Agamben, en su libro Infancia e historia, sostiene que es imposible ponerle palabras al exterminio de personas simplemente porque las víctimas, únicas autorizadas a hablar, ya no están entre nosotros. Para la masacre sólo hay silencio. Pero el dolor de los vivos es inconmensurable. Las únicas palabras que quedan brotan solamente de la boca de los supervivientes o los damnificados. Estos testimonios de la vida en cautiverio o de la vida junto al superviviente visibilizan y se trasmiten a través del dolor de los cuerpos. Estos

1 Se denomina sitios o espacios de la memoria a aquellos lugares que señalan el funcionamiento de centros clandestinos de detención en la última dictadura cívico-militar argentina (1976-1983). En estos lugares sucedieron desapariciones forzadas, torturas, hechos delictivos, detenciones arbitrarias y toda violación de los derechos humanos, todas vejaciones pertenecientes al plan del terrorismo de Estado de la región sur de América Latina. 
cuerpos afectados han podido reaccionar y, desde los primeros años de la dictadura, iniciar el proceso simbólico de reconstrucción de su voz; una voz colectiva, que poco a poco se fue haciendo fuerte en la vida de los iguales.

Juan Mayorga concibe al teatro y al texto dramático como un artificio respetuoso pero provocativo: "el espectador asiste a un conflicto de concreción máxima y, sin embargo, sabemos que lo que hay es una disputa de ideas muy complejas" ("Hay que desobedecer" párrafo 6). Esta lucha de ideas, junto con la capacidad de entretener y de ofrecer la poesía de los cuerpos, es la que deviene pensamiento en el teatro. En el mismo sentido, retomamos las reflexiones de Jean Duvignaud y consideramos al teatro como una de las tantas prácticas sociales que tienen la capacidad de realizar aportes simbólicos al entramado sociocultural donde se inscriben. Dicho aporte es posible en el encuentro entre espectadores y actores, y se concreta sobre la materialidad escénica. Esta mirada del teatro conlleva una suerte de funcionalidad social, o en palabras del sociólogo francés: el teatro es un "instrumento social" (22).

Por su parte, Mario Margulis sostiene que la dimensión simbólica de cualquier sociedad, gira en torno a "la multiplicidad de sistemas de signos que caracterizan las formas de comunicación humana" (24). Así, las comunidades humanas producen signos para comunicarse unos con otros, la experiencia de vivir juntos. Esta comunicación, a medida que transcurre el tiempo, provoca procesos de socialización donde los integrantes de dicha comunidad incorporan y reproducen sistemas de signos que orientan su accionar en la vida social, "haciendo posible la identificación, el reconocimiento y la interacción" (ibídem). De lo anterior sostenemos que es relativamente reciente el proceso de significación alrededor de los grupos afectados por la dictadura. Su consolidación e identidad grupal y el reconocimiento de la experiencia común del horror recién han logrado constituirse como parte visible del ser argentino. En un contexto social siempre adverso a su incorporación, los juicios a los genocidas, la reparación histórica y los espacios dados a la memoria, son apenas tenues paliativos para una herida que sigue sangrando y socavando distancias sociales que parecen inconmensurables.

Guillermo Calderón, lejos de plantear la opción del olvido o la caducidad de la memoria, se concentra en lapidar el presente de las políticas por los derechos humanos en manos dos partidos políticos (y muchas de las veces, en manos del Estado). Calderón comprende a la perfección que el teatro no fue creado para esgrimir afirmaciones. Por esto, lleva a escena los discursos políticos en torno a la recuperación de los Sitios de la Memoria y los somete a un juicio crítico para formularles preguntas. Con cautela quirúrgica, Villa se aproxima a la violencia del terrorismo de Estado para plantear inquietudes propias al cruce política/escena: ¿es posible escenificar el dolor de los cuerpos que atravesaron la tortura? ¿Cuáles son los alcances del arte teatral respecto al pasado más sangriento de la his- 
toria del país? Estas preguntas derivan en la temática central de la obra: ¿cómo y para qué se usan los sitios de la memoria?

Al problematizar los discursos oficiales que operan en nombre de la Memoria, se consiguen apreciar tres posiciones conflictivas en el escenario, sostenidas por tres personajes mujeres: Carla, Macarena y Francisca (aunque dentro de la ficción son homónimas: las tres se llaman Alejandra). Dichas posiciones configuran una situación dramática inicial que conduce a un problema basal: el juego democrático/liberal no funciona (en una votación que no vemos, una de las tres Alejandras, no se sabe cuál, ha anulado el voto con un llamado a la conciencia y moral progresista). Inmediatamente se propone una solución: negociar entre las tres para no tener que votar nuevamente. Sin embargo, la solución es rápidamente descartada, porque una negociación llevaría a una posible situación de corrupción y anulación de la vía democrática. A partir de aquí, se resuelve debatir nuevamente.

Inmediatamente se llega a la acción dramática principal: las tres Alejandras están encargadas de elaborar un proyecto arquitectónico que tiene por objetivo la recuperación del excentro de detención y tortura Villa Grimaldi. Éste va a ser convertido en parte de la vida cultural de la sociedad, pero: ¿cómo va a funcionar? Para imaginar el proyecto, hay en el centro del escenario una maqueta a escala de la Villa. Calderón aborda así un trasfondo social conflictivo: la refuncionalización de los sitios de la memoria, producto de los reclamos de los organismos de derechos humanos, han sido capitalizados para beneficio propio de los partidos políticos progresistas o de la nueva izquierda latinoamericana (Stefanoni). Esto ha generado un malestar y dilema moral entre los supervivientes y afectados. La obra invita a la reflexión sobre el uso de estos espacios en la vida social, debido a que no se trata sólo de acciones simbólicas en favor de la reparación histórica y el saneamiento social, sino de intereses por parte de diversas fracciones partidarias (como el Partido Socialista de Chile, el kirchnerismo o los partidos de izquierda en Argentina). Estos partidos, por momentos, han sorteado convenientemente las consignas iniciales de las organizaciones de derechos humanos para reutilizar sus logros como un pobre "panfleto" de compromiso social, y por este camino, recrear oportunamente su imagen política, con la mira en las urnas.

Carla y Francisca, moderadas improvisadamente por Macarena, son las que esgrimen los dos principales discursos. Carla propone (aunque anticipa que no posee una real convicción) la reconstrucción total del aparato de detención y tortura que existió cuando la Villa estaba en manos de los militares. El ex-centro de detención debe convertirse en una "mansión siniestra" (21) donde los visitantes experimenten lo que las víctimas fueron obligadas a padecer. Así, los concurrentes podrán identificarse con el dolor sufrido por los presos y decir: "esto tiene que haber sentido la gente que sentía" (23). De esta manera, al ingresar a la mansión siniestra, se revive el pasado de los torturados a través de la experiencia del horror diferido. El procedimiento de identificación con los espectadores que van a 
concurrir a la mansión es la herramienta de los mecanismos culturales de dominación del liberalismo. Esta ficción, a la que accede el visitante del museo, es el mundo del terror "tal cual lo vivieron los presos", por esto hay que dejar "las cosas tal cual fueron encontradas" (26) y así lograr una identificación plena con las víctimas del terrorismo (sin necesidad de distancia crítica).

Francisca, en cambio, quiere hacer un museo de arte contemporáneo ultramoderno donde haya performances artísticas que permitan "conocer" el pasado. La idea es convertir la Villa en un espectáculo audiovisual donde la Memoria sea un producto de consumo cultural, ofrecido a través de altísima tecnología y conducido hacia zonas de fantasía (por ejemplo, ofrecer a sólo un click el simulador con la vida del desaparecido, si no hubiera optado por la militancia marxista). El concepto general de Francisca gira alrededor de hacer una suerte de "Disneyworld" (30) del terrorismo de Estado. Esto convierte los eventos históricos en espectáculos analgésicos y agradables. Nada de ponerse a reflexionar o a hacerse preguntas sobre el dolor, el horror de la tortura, la desaparición forzada de personas y el asesinato en manos de militares. En sintonía con el presente neoliberal de la región, la propuesta de convertir a la Villa en un museo recoge el convencionalismo de las ciencias históricas, lo cual convierte a los sitios de la memoria en archiveros sofisticados. En el alboroto feliz del fin de la historia, la idea es tranquilizadora: el terrorismo de Estado, al igual que la era mesozoica, ya sucedió, es parte del pasado y debe quedar ahí, sellado, sólo como un mal recuerdo en una lámina vieja. La experiencia estética que propone Francisca es acogedora. Es más, permite salir del museo y recomendarlo: "me dieron ganas de ser marxista. Y tengo rabia. Me siento culpable de vivir. Es raro, me siento materialista y dialéctica. Pero es lindo. Andá. Tiene calefacción central" (32).

Ambas voces reconstruyen dos formas del mismo discurso hegemónico dominante, propio de la lógica cultural del capitalismo avanzado. Retomando los aportes de Frederic Jameson, quien sostiene que "la producción estética actual se ha integrado en la producción de mercancías en general" (18), nos interrogarnos si la constante urgencia económica de producir sin reparos no ha llegado al punto de comerciar con el ejercicio Memoria, ofreciéndonos experiencias sensibles de diferentes tipos, que buscan saciar el gusto ideológico de los posibles espectadores de la sociedad de consumo. Siguiendo a Jameson, la industria de la cultura contemporánea fascina tanto por sus efectos kitsch —el museo hipermoderno- como por la incorporación de espacios históricos que buscan efectos en el espectador, que anteriormente suponían una sensación de horror: la Mansión Siniestra. Pero, coincidiendo con Calderón, observamos que actualmente tanto lo superficial, como el supuesto horror, ya no escandalizan a nadie. Y esto no queda aquí, sino que se puede ir más allá, porque en realidad, como el espectador hipotético de Villa, estos tipos de discursos complacen al público, institucionalizándose dentro de las matrices oficiales de la cultura de las sociedades occidentales. 
De lo anterior, y, en resumen, la obra Villa expone dos opciones políticas frente a la memoria, que responden a una misma política cultural dominante. Esto queda fundamentado en la acción dramática rectora de la obra: Carla y Francisca sostienen discursos (en los que ni siquiera creen) que conducen a caminos sin salida, a dos posturas que son las dos caras de una misma moneda. Los monólogos de ambos personajes se precipitan en argumentos poco sólidos y la discusión sobre políticas culturales se desvía, por la superficialidad de las propuestas, de la expropiación de niños en la Dictadura (recordemos que las tres protagonistas fueron engendradas en cautiverio), la violación de los derechos humanos y el dolor de los cuerpos.

Por un lado, la identificación total con las víctimas, y por otro, la museificación de la historia del terrorismo, dejando en evidencia la operación política de usar la figura de víctima en provecho de intereses políticos por ambos partidos del llamado "modelo" democrático neoliberal chileno (con alternancias entre los gobiernos de Bachelet, en representación de la "izquierda", y de Piñera, con una posición declarada "de derecha"). Por cualquiera de estos dos caminos, y Calderón lo deja en claro, se ofrece una falsa restitución social de los sujetos oprimidos, y al mismo tiempo algo peor: los estratifica, condena y congela en un lugar simbólico inocuo.

Hay que destacar que Calderón maneja las dimensiones de toda la maquinaria teatral con agudeza. Su práctica representacional coincide con las regulaciones propias de un teatro tradicional (división actores-espectadores, indicaciones sobre la escenografía, unidad de personajes, linealidad temporal, acción única, etcétera). Sin embargo, continuando en el plano social-instrumentista más arriba mencionado, podemos afirmar que los planteos de Villa entran en conflicto con el entramado simbólico social en el que pretende inscribirse. Gracias a la puesta en escena a cargo de la directora de teatro Victoria Monti, la reflexión crítica sobre la vigencia y funcionalidad de los sitios de la memoria se traslada a Córdoba. Una vez aquí, la obra cuestiona quiénes son hoy los afectados por la dictadura, de qué manera se concreta el compromiso social y se le da continuidad a la lucha de los organismos de derechos humanos, y qué usos políticos tienen hoy.

El final de la obra es contundente: si bien el terrorismo de Estado "no debería haber sucedido" (43), ha sucedido. Es un hecho concreto y real del pasado de nuestras sociedades. El trauma postdictadura continúa hasta el presente y se manifiesta en las palabras y en lo sensible de los cuerpos. Lejos estamos de olvidar o perdonar. Entonces la provocación de la obra de Calderón, no sólo expone las preguntas que se vienen planteando, sino que finalmente interpela a la creatividad política hoy: ¿Qué hacer con el dolor y con los responsables de tanto daño? 


\section{La comunidad y el dolor de los cuerpos}

Según Ileana Diéguez, la idea "communitas de dolor" (6) contempla los actos públicos donde se produce el cruce entre evento artístico, protesta ciudadana, intervención urbana y manifestación política. Es importante señalar la relación horizontal que se establece entre los sujetos del grupo social y la experiencia de sociedad real con el otro. De aquí que los individuos, reunidos en una situación pública de encuentro, sin regulaciones estructuradas por alguna legislación oficial o autoridad, sean iguales unos con otros.

Los aportes teóricos de Jean-Luc Lagarce conducen a afirmar que la práctica teatral produce una transformación social, cuando en la misma se forjan y discuten cuestiones de identidad, pertenencia y necesidades sociales. De esta manera, el teatro se convierte en un observatorio de la propia vida en comunidad. Al respecto, el autor sostiene: "El grupo social puede experimentar en escena su propia individualidad o, al menos, lo que se empeña en afirmar como tal" (41). Los afectados por el terror de la dictadura se reconocen en el repertorio teatral que observa sus propios conflictos en la adversa convivencia social. Por ejemplo, reconocen como propia la obra Villa y sus problemáticas, para disolverse en ellas. De esta manera, entre el teatro y la vida social desaparecen los límites. No hay espejo, sino que son lo mismo. En otras palabras, los valores, reglas de convivencia, deseos, problemas y conflictos volcados en la asamblea teatral, son propuesta de acción transformadora.

Continuando con Lagarce, en la asamblea teatral se cristalizan las luchas por el poder y la conservación de los lugares ganados (42). La idea de transformación social comienza cuando se transforma el encuentro teatral, es decir, las formas en que se produce, organiza y administra el espacio del encuentro de los cuerpos. En este sentido, el Ciclo Escena y Memoria se convierte en un caso de estudio donde observamos no sólo las inquietudes discursivas y simbólicas en favor de los Derechos Humanos, sino también nuevas formas de organización del espacio, de convivencia y militancia, materializadas en nuevas convenciones de participación y convivencia, que desarrollaremos más adelante.

Lagarce además sostiene que: "el teatro expresado por cada subgrupo refleja las dificultades particulares que encuentra y su relación con la totalidad del grupo" (43). De aquí que las personas que desde su nacimiento experimentaron la vida democrática, ya no planteen de la misma manera los reclamos por la justicia y la memoria, sino que, como ya venimos observando en la obra Villa, dichos reclamos sean de otra índole y respondan a necesidades de la actualidad social (aunque se trate del mismo sujeto social, identificado plenamente con las experiencias de las víctimas y los supervivientes de los años 70 y 80).

Los trabajos teóricos de Eli Rozik (2014) entran en sintonía con las reflexiones de Lagarce, en tanto afirman que el arte escénico, como práctica social, aparece en los sistemas sociocul- 
turales como un medio que produce una ficción, nuevas reglas o acontecimientos sociales y escénicos, que traducen el mundo, es decir, teorizan la vida social. Esta apreciación nos permite, por un lado, considerar que las representaciones teatrales son utilizadas por las sociedades para producir aportes simbólicos, que pueden o no entrar en conflicto con el sistema sociocultural donde se inscriben. De aquí, nos interesa considerar los aportes discursivos ya señalados de la obra Villa, que exigen un saneamiento del ejercicio de la memoria en las sociedades actuales (para no caer en la sumisión partidaria o en el anquilosamiento de las consignas). Por otro lado, al considerar al teatro como una práctica social donde las convenciones de participación siempre responden a intereses políticos e ideológicos, nos interesa establecer las relaciones entre la modalidad participativa política y teatral del evento artístico Ciclo Escena y Memoria en la ciudad de Córdoba, y la urgencia del saneamiento de la memoria propuesta por la obra Villa (obra estrenada en el Teatro Real de la ciudad de Córdoba y representada en el mencionado Ciclo).

Así como en Santiago de Chile, Villa Grimaldi es uno de los símbolos de las atrocidades y violaciones de los derechos humanos, en la ciudad de Córdoba existió, entre otros, el Departamento de Inteligencia de la Policía de la Provincia de Córdoba, conocido en la jerga como "D2". En el año 2007 los organismos de derechos humanos, luego de una larga contienda política y con apoyo gubernamental, logran que las instalaciones del ex-centro clandestino de detención sean puestas a disposición de la Comisión Provincial de la Memoria. La Comisión, entre otras acciones, decide refuncionalizar el D2 para habilitar allí un sitio de la memoria. Actualmente dicho Departamento fue desmantelado y en su lugar funciona el Archivo Provincial de la Memoria. Este Archivo es un organismo autónomo del área Ministerial de Justicia del Poder Ejecutivo (Provincia de Córdoba), y tiene por objetivos, entre otros, proveer instrumentos legales necesarios para la búsqueda de la verdad histórica y la justicia, allanando el camino de la reparación social respecto a las violaciones de los derechos humanos y falta de libertades ocurridas en la dictadura. Además, se propone reutilizar el espacio del D2 garantizando el libre acceso del público al testimonio histórico edilicio.

En el 2009 el reconocido director de teatro independiente, Jorge Villegas, convoca a diversos artistas y propone la creación del Ciclo Escena y Memoria. Se constituye así un espacio multidisciplinar donde hacedores del teatro, el cine, la literatura y las artes visuales, así como también referentes de la comunicación y el ámbito cultural y político de Córdoba, reflexionan, se manifiestan y se expresan públicamente sobre el más nefasto golpe militar de la historia argentina. Villegas comenta sobre los inicios: "El traspaso de esos espacios de represión a los organismos de Derechos Humanos y la reanudación de los juicios a los genocidas, abrían una expectativa histórica y me pareció que el teatro debía acompañar esa instancia" (citado en Carpintero párrafo 1). Este momento propi- 
cio para el ejercicio de la memoria permitió continuar con el trabajo de revisión histórica y, novedosamente, volver a darle sentido al pasado común, muchas veces hermético a las palabras. Villegas recuerda:

El ciclo pasó por distintas etapas desde que Néstor Kirchner visitó La Perla y decidió la construcción de los espacios de memoria. Fue una bisagra ante la cual los artistas expresamos una fuerte intención de trabajo. Recuerdo que además nos invitaron a participar en el Festival de Teatro x la Memoria de Rosario (citado en Molinari, "El teatro tampoco olvida" párrafo 2).

Los últimos años de gobierno neoliberal (que presidió Mauricio Macri entre el 2015 y el 2019) fueron tiempos sumamente adversos. Se arremetió directamente contra las instituciones defensoras de los derechos humanos, se despresupuestaron los proyectos y se realizaron aberrantes declaraciones, como la del radical Oscar Aguad, quien tras ganar las elecciones y asumir como Ministro de Defensa, aseguró, por ejemplo, que el Archivo Provincial de la Memoria iba a cerrarse para poner en su lugar las oficinas de Registro del Automotor. Pocos meses después, la Comisión Provincial de la Memoria lo denunciaría penalmente por tratar de desmantelar el equipo de Archivo y Pruebas Judiciales (equipo de profesionales que relevan y analizan los archivos de las Fuerzas Armadas), de donde surgieron importantes denuncias hacia miembros de las cúpulas militares (Hayon).

En un primer momento parecen incompatibles la celebración teatral y el espacio donde fueron torturados los detenidos en la dictadura. No obstante, hay entre el teatro y ese espacio en particular, una complicidad que apuesta por la abolición de la tristeza, por el ejercicio de la memoria y la reparación social. Dicha complicidad tiene fundamento no solamente en que se trata de un encuentro entre artistas por un lado y espectadores por otro, sino también en que se trata de un espacio público donde tiene lugar la compañía afectiva e ideológica. Villegas afirma dos cuestiones al respecto. En primer lugar: lo político emerge del Ciclo cuando se produce el cruce entre memoria individual y colectiva, pero, sobre todo, en el encuentro de "ciudadanos-artistas dispuestos a escucharse, discutir, poner en marcha algo entre muchos" (citado en Carpintero párrafo 7) y actualizar la lucha contra la injusticia social. En segundo lugar, Villegas aclara:

[...] no es un festival de teatro que organizan un par de célebres personajes, sino que es un hecho bien colectivo donde se discute mucho, aun con asimetrías y disparidades en los volúmenes de militancia e instancias en las que cada cual tiene una relación particular con los Derechos Humanos, el teatro, la política y la sociedad. Es un espacio de militancia (citado en Reales párrafo 9). 
La reunión de hacedores artísticos y militantes por los derechos humanos posibilita la creación de un grupo social, alrededor de una acción política que formula una nueva forma de organización específica. Esta organización propicia al sector, identificado con el sufrimiento de las víctimas del terrorismo de Estado, una instancia más al proceso de conformación de la identidad. Al mismo tiempo, la reunión es un modo de visibilidad y esgrime una voz propia que se activa en torno al reclamo de justicia y memoria, pero también alrededor de las situaciones de injusticias que se viven día a día. La práctica teatral, entonces, cobra sentido en función de la reconstrucción y reelaboración de la historia reciente de nuestro país, pero también de la consolidación de la identidad de sectores sociales afectados y próximos a las víctimas y a la resolución de las injusticias sociales.

El Ciclo Escena y Memoria, como actividad del teatro independiente, presenta una grilla de espectáculos teatrales que conviven con actividades de intervención política y denuncia. En principio, dentro del D2 no hay sala de teatro alguna, por lo que se toman los espacios y se adaptan las obras de teatro para poder representarlas allí. En este procedimiento de adaptación espacial comienzan a vislumbrarse las nuevas convenciones de participación teatral. En primer lugar, se disuelven los límites espaciales para las producciones artísticas. Además, los participantes ya no ingresan como espectadores a una sala común, sino que lo hacen predispuestos a otro tipo de intercambio simbólico, ideológico y afectivo. De este modo se comienzan a generar pequeños intersticios espaciales donde el protagonismo se desplaza de las obras de teatro al encuentro de los cuerpos y la compañía afectiva.

Villegas señala que el Ciclo, en sus inicios, era un espacio exclusivo para obras de teatro y que, con el paso de los años, fue transitando hacia nuevas formas de la experiencia escénica: "Al inicio éramos un grupo de teatristas que nos íbamos a juntar e invitar a otros colegas que estaban haciendo un teatro con politicidad y que además eran compañeros que veíamos en las calles, que ponían el cuerpo, que compartían la ética del teatro" (citado en Reales párrafo 6). Por esta razón, el Ciclo Escena y Memoria convoca a obras de teatro con temáticas explícitamente próximas a la dictadura, y además suma espectáculos y eventos que dialogan con diferentes problemas sociales actuales. Este cambio en la modalidad de convocatoria del Ciclo actualiza las consignas y reclamos y confiere al espacio una nueva forma de resistencia a las injusticias sociales. Como afirma Selbin: "la resistencia puede también referir a una forma de insurgencia que se caracteriza por el rechazo a cooperar activamente y a apoyar al régimen actual y sus autoridades; aun cuando esto pueda parecer pasivo, se trata de una actividad, de una acción" (24). De lo anterior consideramos que tanto el Archivo como el Ciclo constituyen uno de los espacios clave de la cultura de resistencia cordobesa, donde se repudia el Terrorismo de Estado de la dictadura, pero también cualquier hecho de violencia por parte de las fuerzas públicas en democracia. 
De esta manera, y en las consecutivas ediciones del Ciclo, encontramos un evento artístico y político que genera una sutil pero constante transformación del ejercicio de la memoria, así como de la actualización del rol político del teatro independiente. Desde esta perspectiva, el evento en sí mismo se convierte en acción de transmisión del saber social y artístico. La fragmentación de espectáculos, la lectura de poesía, la convivencia, el pacto tácito del silencio y de compartir el dolor de los cuerpos, toma distancia de cualquier tipo de convencionalismo representativo clásico. Es que participar del Ciclo va más allá de la expectación de espectáculos con temáticas de la dictadura. El Ciclo es un evento que excede (y nunca deja de contener) al teatro, desajustando las convenciones de participación legitimadas por el campo teatral y provocando una situación novedosa a partir de la ampliación de los límites y posibilidades de la asamblea teatral.

El Ciclo Escena y Memoria invita a concurrir y poner el cuerpo. Es en los cuerpos reunidos donde circula el diálogo, la militancia política, la reivindicación de valores por lo humano. Sostiene Villegas al respecto: "recuerdo cuando Luciano Benjamín Menéndez dijo que habían sido derrotados culturalmente. Lo dijo en primera persona, durante el juicio" (citado en Molinari, "El teatro tampoco olvida, párrafo 5). La "victoria" del Ciclo es la acción cultural que reivindica una ciudadanía comprometida con las políticas de derechos humanos, pero que no sólo atiende el terror y la miseria de la última Dictadura, sino que también tiene en cuenta, como aclara Villegas, "la violencia en los barrios entre vecinos y a la violencia policial. El teatro es una de las voces, en ese acto único en cada función, que dice lo suyo" (citado en Molinari, "El teatro tampoco, párrafo 6). El Ciclo Escena y Memoria recupera el tiempo y el lugar para la reunión y la comunidad, cuestiones socavadas por el poder y las lógicas culturales dominantes. Así lo contempla Villegas, que en cada edición del ciclo percibe "una necesidad de juntarse con colegas que trabajan políticamente el campo de lo escénico y también una necesidad de participar de hechos honestos, colectivos, verdaderos. Allí radica la continuidad de Escena y Memoria; no es de nadie, es de los que lo hacen y punto" (citado en Carpintero párrafo 4).

Se entiende que el ejercicio de la memoria durante el Ciclo es inteligencia colectiva que nunca se manifiesta como algo a comprender de manera taxativa ni con mensajes unívocos, sino más bien apuesta por una experiencia de convivencia para hacerle frente al espanto de la experiencia sufrida en el pasado, pero también al presente, y es fundamentalmente una instancia para pensar próximas acciones y formas de organización para la reparación social. Aquí hay una toma de posición, una apuesta, un gesto político. Es hacer con lo que fuimos y con lo que somos.

Entonces la experiencia del Ciclo no es sólo una manifestación en la calle o un festival de teatro convencional, sino una contingencia para restituir sentidos múltiples, fronterizos y ambiguos, pero sobre todo impredecibles. Hacia el interior del grupo social afectado 
y reunido, donde los cuerpos son permeables a las sensaciones, la coexistencia colectiva escapa a las condiciones de convivencia normadas, configurando un nuevo espacio y experiencia estético-social y escénica. De este modo, cada participante del Ciclo se conmueve según sus propias asociaciones afectivas y simbólicas, en un proceso de mutua estimulación imprevisible, pero siempre en complicidad con los demás.

Por este camino, el ejercicio de la memoria en el Ciclo se afianza en las experiencias traumáticas del pasado y también contempla un contenido crítico amplio hacia las políticas estatales de la actualidad; es espacio de resistencia e identidad, y no deja de mirar el entorno social del que forma parte; evita el anquilosamiento de las consignas políticas y da lucha en el presente.

\section{Redefiniciones del compromiso social en el teatro independiente}

En una época de confusión organizada, de desorden decretado, de arbitrariedad planificada $y$ de humanidad deshumanizada...

Nunca digan: "Es natural", para que todo pueda ser cambiado.

Bertolt Brecht

Como ya se dijo, a diferencia de las representaciones teatrales del terrorismo (que incontables veces funcionaron como descompresión de la angustia y la visibilización de los testimonios), la obra de teatro Villa expone el conflicto intrínseco a dos discursos en apariencia humanitarios, pero que en su trasfondo responden a la matriz cultural hegemónica del capitalismo avanzado, dejando en evidencia el uso partidario de la Memoria y de los discursos por los derechos humanos en la vida democrática actual.

La asamblea teatral del Ciclo Escena y Memoria, en una actitud propositiva, encuentra una respuesta concreta al uso de los sitios de la memoria: se continúa con las consignas de reparación social por las aberrantes desapariciones de la dictadura, pero también se redefinen en el encuentro de los cuerpos: lo amoroso, lo dialógico y lo afectivo.

La violencia de la dictadura dejó marcas imborrables. El dolor quedó inscrito en el cuerpo. Son marcas y cicatrices en la piel de los supervivientes. Este dolor se acarrea en gestos involuntarios, llantos mudos, gritos desaforados, tonos de la voz o simplemente miradas. Y son estos cuerpos los que acuden a la reunión y generan complicidad pública en el teatro, para encontrar sosiego, refugio y pertenencia. De esta manera, el dolor se 
transita del mismo modo. El dolor se libera en el encuentro comunitario con el otro. Por esto la asamblea teatral es elegida, una vez más, como el espacio a través del cual exponer y compartir este dolor. Hay que hacerlo común para que se disuelva. Pero no se trata de una falsa catarsis, sino que es la habilitación de un espacio donde practicar y hacer presente la solidaridad afectiva que, tal vez de una manera inconsciente y vaga, repara algo de los traumas de los cuerpos afectados por el terrorismo. Pero nuevamente: no se trata de un lugar donde sólo se cumple con la importante necesidad de compartir el olvido; hay algo más allí.

El Ciclo coincide con los incisivos planteos que encontramos en la obra de Calderón y crea las condiciones artísticas necesarias para la escenificación de las problemáticas sociales más urgentes, vinculadas a la violencia por parte del Estado provincial. Una vez más, el teatro habilita el desplazamiento hacia nuevos espacios de la militancia política y la convivencia social. El arte, la ética y la communitas se contagian en el ejercicio de la memoria, ofreciendo una nueva densidad experimental a sus participantes, donde por un lado se vuelven superfluos los límites entre hacedores artísticos y espectadores y, por otro lado, desde el dolor de los cuerpos, se levanta la mirada hacia las necesidades del presente. En este sentido, el teatro no sólo es discurso público donde se recuerda y denuncia, sino que se convierte en una acción pública que sirve al proceso de reconstrucción identitario desde lo corporal, lo solidario y su cualidad intrínseca de reunir personas.

De lo anterior se observa un conjunto de procedimientos escénicos que redefinen y actualizan las convenciones de producción, organización y expectación de la asamblea teatral, así como también las formas de organización y acción de la militancia política en materia de derechos humanos. La necesidad de cuerpos emocionados, sensibilizados y afectados habita de vida y presente el espacio de muerte, donde funcionó el centro de detención. Por dar un ejemplo, Laura Ortiz, reconocida clown del teatro independiente cordobés, afirma que el Ciclo Escena y Memoria fue para ella un espacio donde vivió la complicidad y la afección de los cuerpos, pero sin descuidar su compromiso social:

cada artista se acerca desde su inquietud, por su propia convicción de estar, de ser parte; porque entendemos que también estos son tiempos que pretenden avasallarnos, desprestigiarnos. Entonces es fundamental ocupar los espacios, visitar y habitar los sitios, insistir y persistir. Escena y Memoria permite que se resignifiquen los espacios, se hacen presentes las voces, esos muros que fueron testigos del horror lo son también del abrazo, de la poesía. Es una rebeldía amorosa (citado en Carpintero párrafo 7). 
Esta actitud de rebeldía amorosa no es otra cosa que un espacio común de militancia política, donde los participantes se hacen cargo de las urgencias sociales y aprovechan para accionar políticamente, no sólo durante la semana del 24 de marzo ${ }^{2}$ sino todo el resto del año. Por dar otro ejemplo, en la inauguración del año 2017, ocurrida en la plaza central del barrio Juniors, la señora Viviana Alegre reclamó por la situación de injusticia con relación a la desaparición de su hijo, Facundo Rivera Alegre (conocido como "el Rubio del pasaje") hacía 5 años, en plena democracia y a manos de la Policía Provincial de Córdoba. Seguido al acto comenzaba una obra de teatro.

Tenemos entonces que en esa plaza se materializa, además del reclamo expreso que se anota en la agenda de derechos humanos, la asamblea teatral, que reúne personas dispuestas a poner el cuerpo. Esta disposición se configura alrededor del reconocimiento de una comunidad horizontal y colectiva, del dolor. Esta inauguración fue también parte del luto. Varios familiares, en representación de las familias que, en todo el país, año tras año, sufren la desaparición de algún ser querido a manos de la policía, pudieron encontrarse. A partir del reclamo conforman una comunidad moral que exige justicia y un freno a la violencia policial. Pero no es un luto amargo, oscuro y triste, sino que es un luto en asamblea. Un luto que despierta la reflexión crítica que propicia la denuncia, corriendo los límites y llegando a manifestarse por la solución del desempleo, en contra de la criminalización de la protesta social, de la violencia machista y los feminicidios, por la justicia por la Masacre de Avellaneda del año 2002, por la disolución de la complicidad del Estado provincial con el narcotráfico y por cuestiones ambientales como el desmonte o el uso de agroquímicos. Y como se viene señalando, hay acciones ciudadanas y legales, es decir, acciones reales sobre el entramado social.

De esta manera, el Ciclo Escena y Memoria, en su calidad de evento del teatro independiente cordobés, modifica a la sociedad interviniendo el espacio público para darle cuerpo y voz a los momentos traumáticos de la más brutal dictadura del país, pero también para atender a las injusticias sociales actuales. En dicho desplazamiento se le da continuidad a lo humanitario, ampliando los alcances del ejercicio de la memoria, y además se redefine la zona de contagio entre teatro y militancia política, generando nuevas formas de participación y organización, pero fundamentalmente: ampliadas responsabilidades sociales.

2 Esta fecha es el día nacional por la memoria por la verdad y la justicia, y se conmemora a las víctimas de la última dictadura cívico-militar, iniciada el 24 de marzo de 1976 y autodenominada "Proceso de Reorganización Nacional”. 


\section{Fuentes consultadas}

Agamben, Giorgio. Infancia e historia. Buenos Aires: Adriana Hidalgo, 2001.

Alegret, Mauro. Condiciones y convenciones del teatro independiente cordobés. Tesis de doctorado en Estudios Sociales de América Latina, Universidad Nacional de Córdoba, 2017.

Calderón, Guillermo. Teatro II. Santiago de Chile: LOM, 2012.

Carpintero, Verónica. "Diez años de teatro y poesía para habitar muros del horror”. Un Rato, Facultad de Artes de la Universidad Nacional de Córdoba, 2 de mayo de 2018, unrato.artes.unc.edu.ar/diez-anos-de-teatro-y-poesia-para-habitar-los-muros-delhorror/, consultado 14 de febrero 2020.

Diéguez, Ileana. Cuerpos sin duelo. Iconografías y teatralidades del dolor. Córdoba: Documenta / Escénicas, 2013.

Dubatti, Jorge. Introducción a los estudios teatrales. Buenos Aires: Atuel, 2011.

Dubatti, Jorge. "El teatro argentino en la postdictadura (1983-2010): época de oro, destotalización y subjetividad”. Stichomythia, núms. 11-12, 2011, pp. 71-80.

Duvignaud, Jean. Sociología del teatro. México: Fondo de Cultura Económica, 1966.

Hayon, Alejandra. "Aguad quiere borrar la memoria". Página 12, 22 de diciembre de 2017, www.pagina12.com.ar/84475-aguad-quiere-borrar-la-memoria, consultado 1 de marzo 2020.

Jameson, Frederic. Posmodernismo o lógica cultural del capitalismo avanzado. Buenos Aires: Paidós, 2005.

Lagarce, Jean-Luc. Teatro y poder en Occidente. Buenos Aires: Atuel, 2007.

Lladó, Albert. "Hay que desobeceder al espectador. Entrevista a Juan Mayorga”. La Vanguardia, 23 de junio de 2014, www.lavanguardia.com/libros/20140623/54410309275/ juan-mayorga-desobedecer-al-espectador.html, consultado 16 de febrero 2020.

Margulis, Mario. Sociología de la cultura: conceptos y problemas. Buenos Aires: Biblios, 2011. Mayorga, Juan. "El teatro piensa; el teatro da qué pensar". Primer acto. Cuadernos de investigación teatral, 337, 2011, pp. 15-16.

Molinari, Beatriz. "Jorge Villegas es premiado por su inquebrantable lealtad al teatro". La voz, 17 de octubre de 2017, vos.lavoz.com.ar/escena/jorge-villegas-es-premiado-por-su-inquebrantable-lealtad-al-teatro, consultado 1 de marzo 2020.

Molinari, Beatriz. "El teatro tampoco olvida: comienza el ciclo Escena y Memoria”. La voz, 19 de marzo de 2017, vos.lavoz.com.ar/escena/el-teatro-tampoco-olvida-comienza-el-ciclo-escena-y-memoria, consultado 15 de febrero 2020.

Quijano, Aníbal. "Colonialidad del poder, eurocentrismo y América Latina”. La colonialidad del saber: eurocentrismo y ciencias sociales. Perspectivas Latinoamericanas, editado por Edgardo Lander. Buenos Aires: CLACSO, 2000, pp. 246-280. 
INVESTIGACIÓNTEATRAL

Revista de artes escénicas y performatividad

Vol. 11, Núm. 18

octubre 2020-marzo 2021
Ciclo Escena y Memoria:

una rebeldía amorosa

Mauro Alegret

Rozik, Eric. Las raíces del teatro. Buenos Aires: Colihue, 2014.

Reales, Ana. "Escena y Memoria: un espacio de resistencia". La tinta, 22 de marzo de 2017, www.latinta.com.ar/2017/03/escena-y-memoria-un-espacio-de-resistencia/, consultado 15 de febrero 2020.

Selbin, Eric. El poder del relato. Buenos Aires: Interzona, 2014.

Stefanoni, Pablo. "La lulización de la izquierda latinoamericana". Le monde diplomatique, 2014, www.eldiplo.org/notas-web/la-lulizacion-de-la-izquierda-latinoamericana/, consultado 1 de marzo de 2020. 